OPEN ACCESS

Edited by:

Einar Vargas-Bello-Pérez, University of Copenhagen, Denmark

Reviewed by:

Shengyu Xu,

Sichuan Agricultural University, China

Jing Wang,

Beijing Academy of Agriculture and

Forestry Sciences, China

*Correspondence:

Wutai Guan

wtguan@scau.edu.cn

†These authors have contributed equally to this work

Specialty section: This article was submitted to Animal Nutrition and Metabolism, a section of the journal

Frontiers in Veterinary Science

Received: 05 March 2021 Accepted: 21 May 2021

Published: 21 July 2021

Citation: Chen F, Lv Y, Zhu P, Cui C, Wu C, Chen J, Zhang S and Guan W (2021)

Dietary Yucca schidigera Extract

Supplementation During Late Gestating and Lactating Sows Improves Animal Performance,

Nutrient Digestibility, and Manure Ammonia Emission.

Front. Vet. Sci. 8:676324. doi: 10.3389/fvets.2021.676324

\section{Dietary Yucca schidigera Extract Supplementation During Late Gestating and Lactating Sows Improves Animal Performance, Nutrient Digestibility, and Manure Ammonia Emission}

\author{
Fang Chen ${ }^{1,2 t}$, Yantao Lv ${ }^{1,3,4 t}$, Pengwei Zhu ${ }^{1}$, Chang Cui ${ }^{1}$, Caichi Wu ${ }^{1}$, Jun Chen ${ }^{1}$, \\ Shihai Zhang ${ }^{1}$ and Wutai Guan ${ }^{1,2 *}$
}

${ }^{1}$ Department of Animal Science, South China Agricultural University, Guangzhou, China, ${ }^{2}$ National Engineering Research Center for Breeding Swine Industry, Guangzhou, China, ${ }^{3}$ College of Animal Science and Technology, Zhongkai University of Agriculture and Engineering, Guangzhou, China, ${ }^{4}$ Innovative Institute of Animal Healthy Breeding, College of Animal Sciences and Technology, Zhongkai University of Agriculture and Engineering, Guangzhou, China

This study was conducted to investigate the effect of dietary Yucca schidigera extract (YSE) supplementation to sow performance, nutrients digestibility and ammonia emission of manure. Total 80 sows were randomly divided into 4 groups and fed with either control, control $+0.06 \%$ YSE, control + 0.12\% YSE or control + 0.24\% YSE diet from day 80 of gestation to day 21 of lactation. The results showed that dietary YSE supplementation resulted in trends toward a reduced number of stillbirth piglets $(P=0.08)$, weak piglets $(P=0.06)$, pre-weanling mortality $(P=0.04)$ and diarrhea $(P=0.03)$, and improved apparent digestibility of dry matter $(P=0.04)$. Besides, YSE supplementation significantly increased catalase activity $(P=0.02)$ while decreasing malonaldehyde levels $(P=0.04)$ in sow blood. Furthermore, the loss of total nitrogen, urea nitrogen and ammonia nitrogen in sow manure were significantly reduced with supplementation of YSE. In summary, supplementation of YSE in sow diet during late gestation and lactation could improve sow and litter performance, nutrient digestibility, and reduce nitrogen loss in sow manure during storage.

Keywords: animal performance, antioxidative, manure, nitrogen loss, sow, Yucca schidigera extract

\section{INTRODUCTION}

Ammonia emissions from animal facilities are frequently the subject of odor complaints and public concern due to the possibility of their negative health effects in both humans and animals. Livestock and poultry may develop a variety of disorders when exposed to high levels of ammonia for extended periods of time $(1,2)$. Therefore, it is very important to develop efficient strategies to reduce $\mathrm{NH}_{3}$ emissions from livestock manure. 
Yucca schidigera, a species of the yucca plant that is native to the southwestern United States and Mexico, is rich in natural steroid saponins, numerous enzymes, antioxidants and resveratrol (3). In recent times, yucca plant extracts have been widely used as natural additives in the food and livestock industries (4). Yucca schidigera extract (YSE) has been shown to not only improve livestock and poultry performance, including weight gain, feed efficiency and health (5-7), but also reduce ammonia emissions from animal manure and consequently control odor in animal facilities as well (8-10).

Although previous studies have been conducted to investigate the effect of dietary YSE supplementation on performance and $\mathrm{NH}_{3}$ emission in pig industry, most of these studies focused on growing pigs rather than sows which produce more manure than young pigs. Therefore, different levels of YSE were supplemented into sow diets during late gestation and lactation to evaluate their effects on animal performance, nutrient digestibility, blood gas parameters, and oxidative status in present study. Furthermore, effect of YSE on total nitrogen, ammonia nitrogen and urease activity in sow manure during storage with time passage were also determined to investigate the effect of YSE to ammonia emission.

\section{MATERIALS AND METHODS}

The experiment was carried out according to Chinese guidelines for animal welfare and the National Institutes of Health guide for the care and use of Laboratory animals. All the experimental procedures performed in this study were approved by the South China Agricultural University Animal Care and Use Committee.

\section{Animals and Diets}

The YSE used in this study was a commercial product provided by Shanghai Hengtai Company, and it contained $>10.5 \%$ saponin and $>318 \mathrm{mg} / \mathrm{kg}$ resveratrol. A total of 80 sows (Large White, four to six parities) from the Huizhou Swine Breeding Center were used in this study, and they were housed in individual feeding stalls with free access to water during the entire trial. Sows were allotted to 4 treatment groups with 20 sows per treatment, and they were fed diets containing either $0.0 \%$ (control), 0.06 , 0.12 , and $0.24 \%$ YSE from day 80 of gestation through day 21 of lactation. The composition of the experimental diets and their nutrient levels are described in Table 1. The nutrient levels of the diets met or exceeded the requirements for sows during late gestation and lactation. The sows were kept in single crates $(0.6$ $\times 2.0 \mathrm{~m}$ ) from insemination to $\mathrm{d} 110$ of gestation, at which time they were transported to the farrowing facility where they were placed in individual farrowing crates $(2.4 \times 2.4 \mathrm{~m})$. All sows were managed in the gestation facility from day 80 to day 109 of gestation and then transferred to lactation facilities to prepare for farrowing. Feed consumption was limited to $2.5 \mathrm{~kg} / \mathrm{d}$ during gestation and was then increased progressively by $0.5 \mathrm{~kg} / \mathrm{d}$ during lactation. Within $48 \mathrm{~h}$ postpartum, litter size was standardized

Abbreviations: YSE, Yucca schidigera extract; ADG, Average daily gain; MDA, Malonaldehyde; CAT, Catalase; T-AOC, Total antioxidant capacity; SOD, Superoxide dismutase; GSH-Pxm Glutathione peroxidase; GSH, Glutathione; UN, Urine nitrogen; TP, Total protein.
TABLE 1A | Composition and nutritional value of the diet (as-fed basis).

\begin{tabular}{lcc}
\hline Item & Gestation & Lactation \\
\hline Ingredient (\%) & 66.00 & \\
Corn & 20.00 & 61.00 \\
Soybean meal & 10.00 & 25.00 \\
Bran & - & 6.00 \\
Fish meal (62.8\%) & - & 2.00 \\
Soybean oil & 4.00 & 2.00 \\
Premix & 100.00 & 4.00 \\
Total & & 100.00 \\
\hline
\end{tabular}

a Vitamin and mineral premix supplied per kilogram of complete diet: $100 \mathrm{~g} \mathrm{NaCl}$, $\left.\left.50 \mathrm{mg} \mathrm{Zn} \mathrm{(} \mathrm{ZnSO} 4 \cdot \mathrm{H}_{2} \mathrm{O}\right), 80 \mathrm{mg} \mathrm{Fe}\left(\mathrm{FeSO} 4 \cdot \mathrm{H}_{2} \mathrm{O}\right), 20 \mathrm{mg} \mathrm{Mn} \mathrm{(MnSO} 4 \cdot \mathrm{H}_{2} \mathrm{O}\right), 5 \mathrm{mg} \mathrm{Cu}$ (CuSO4.5H2O), $0.14 \mathrm{mg}$ I (Cal2O6), $0.3 \mathrm{mg} \mathrm{Se}$ (Na2SeO3), 13,000 IU vitamin A, 4000 IU vitamin D3, $30 \mathrm{IU}$ or $90 \mathrm{IU}$ vitamin $\mathrm{E}, 4 \mathrm{mg}$ vitamin $\mathrm{K} 3,4 \mathrm{mg}$ vitamin $B 1,10 \mathrm{mg}$ vitamin B2, $4.8 \mathrm{mg}$ vitamin B6, $0.034 \mathrm{mg}$ vitamin B12, $40 \mathrm{mg}$ niacin, $20 \mathrm{mg}$ d-pantothenate, $2 \mathrm{mg}$ folic acid, and $0.16 \mathrm{mg}$ d-biotin.

TABLE 1B | Composition and nutritional value of the diet (as-fed basis).

\begin{tabular}{lcc}
\hline Nutritional level $^{\mathrm{a}}$ & Gestation & Lactation \\
\hline Apparent digestibility (MJ/kg) & 13.21 & 13.90 \\
Crude protein & 15.51 & 17.96 \\
Crude fat & 3.12 & 4.89 \\
Dietary fiber & 3.86 & 3.39 \\
Ash & 5.16 & 5.09 \\
Ca & 0.86 & 0.86 \\
Total P & 0.52 & 0.57 \\
Lysine & 0.78 & 0.95 \\
Methionine + cystine & 0.55 & 0.60 \\
Threonine & 0.66 & 0.71 \\
Tryptophan & 0.21 & 0.23
\end{tabular}

a Nutritional levels were analyzed value except calculated apparent digestibility.

to $9 \pm 1$ piglets per litter by cross-fostering within the same treatment (a total of 200 piglets per treatment), and standard practices were applied as follows: iron injection $(200 \mathrm{mg} \mathrm{Fe}$ as gleptoferron), needle teeth and tail clipping. The piglets were weaned at $\mathrm{d} 21$ of lactation.

\section{Sample and Data Collection Sow and Litter Performance}

Once farrowing was completed, the number of piglets born (total, live, stillborn, mummy), litter birth weights, and individual piglet weights were recorded. At days 2, 7, 14, and 21 of lactation, litter size and litter weights were recorded, as well as the feed intake of each lactating sow and oestrus rate at day 5 and 7 after weanling.

\section{Blood Sampling}

At day 100 of gestation and day 15 of lactation, blood samples ( $20 \mathrm{~mL}$ per sow) from 6 sows per treatment were taken by ear venipuncture using heparinized vacutainer tubes $(10 \mathrm{~mL})$ and normal tubes $(10 \mathrm{~mL})$. Plasma was harvested after centrifugation at 3,000 $\times \mathrm{g}$ for $10 \mathrm{~min}$ for subsequent blood gas analysis, and serum was harvested to assess antioxidative capacity. 


\section{Feces Sampling for Nutrient Digestibility}

Fresh fecal samples were collected quantitatively twice daily from each sow from day 93 to day 95 of gestation and from day 14 to day 16 of lactation, and they were stored at $-20^{\circ} \mathrm{C}$ immediately after collection. Ash insoluble in hydrochloric acid was used as an indigestible marker to calculate the apparent nutrients total tract digestibility (11). Fecal samples were dried in a 50 r̆C forcedair drying oven and then ground to pass through a $1 \mathrm{~mm}$ screen before chemical analysis.

\section{Feces and Urine Sampling for Nitrogen Related Parameters}

Fresh feces and urine samples were collected from sows on day 100 of pregnancy and day 15 of lactation and $10 \%$ hydrochloric acid was added immediately to fix nitrogen. Feces and urine samples from individual sows were collected separately in clean plastic bags to ensure that there was no mixing prior to the ensuing experiments. Both the feces and urine samples were taken directly upon excretion from the sows to prevent any contact with the barn floor. All samples were kept at $4^{\circ} \mathrm{C}$ during transportation and then stored at $-80^{\circ} \mathrm{C}$ until analysis.

\section{Colostrum and Milk Sampling}

The cololstrum and milk samples were sampled after intramuscular injection of 20 IU oxytocin within $24 \mathrm{~h}$ after parturition,on day 14 and day 21 of lactation. The samples were immediately frozen and stored at $-80^{\circ} \mathrm{C}$ until analysis.

\section{Chemical Analysis \\ Diet and Feces Composition}

The dry matter, crude protein, crude fiber, starch, phosphorus, calcium, copper, iron, zinc and manganese content of the diets were assessed according to the Chinese standard methods ( $\mathrm{GB} / \mathrm{T}$ 6435-2014, GB/T 6432-1994, GB/T 6434-2006, GB/T 6433-2006, GB/T 20194-2006, GB/T 6437-2002 and GB/T 13885-2017).

\section{Antioxidant Status}

The antioxidant status, including total antioxidant capacity (T-AOC), superoxide dismutase (SOD), glutathione peroxidase (GSH-Px), glutathione (GSH), catalase (CAT) and malonaldehyde (MDA) levels in plasma, colostrum and milk were measured as described in our previous studies (12), using commercially available kits (Nanjing Jiancheng Bioengineering Institute, Nanjing, China) according to the manuals.

\section{Blood Analysis}

Blood gas including $\mathrm{pH}, \mathrm{PO}_{2}, \mathrm{TCO}_{2}, \mathrm{HCO}_{3}^{-}, \mathrm{PCO}_{2}$ and $\mathrm{NH}_{3}$ in sow plasma were analyzed using an i-STAT 1 blood gas system (Abbott Laboratories, Chicago, IL, USA). The serum uterine nitrogen (SUN) and total protein (TP) in sow serum were measured using commercially available kits (Nanjing Jiancheng Bioengineering Institute, Nanjing, China) according to the manual.

\section{Fecal Urease Activity}

Urease activity measurements in fresh feces were measured within 2 days using the indophenol blue colorimetry method described previously (13).

\section{Fecal Ammonia Nitrogen Content}

The ammonia nitrogen content of fresh feces was measured according to Chinese standard methods (HJ535-2009).

\section{Total Nitrogen and Urea Nitrogen Content in Manure}

Sow manure was made by mixing $60 \mathrm{~g}$ fresh feces and $60 \mathrm{ml}$ of urine in a beaker. The fresh manure was then made homogenous by magnetic stirring at $300 \mathrm{rpm}$ for $5 \mathrm{~min}$. Approximately $6-8 \mathrm{~g}$ of manure were taken from the beaker to measure total nitrogen and urea nitrogen after $0,12,24,48,72$, and $120 \mathrm{~h}$ of mixing (14). Total nitrogen was determined using the Kjeldahl method and urea nitrogen was determined using a commercial kit (Nanjing Jiancheng Bioengineering Institute, C013-2-2, Nanjing, China) according to the manual. Nitrogen loss during storage were calculated by total nitrogen at the beginning minus nitrogen content in the corresponding storage time.

\section{Data Analysis}

All experimental data except for oestrus rate were analyzed by one-way analysis of variance (ANOVA) using SPSS 17.0 (SPSS, INC., Chicago, IL, USA) to determine whether significant variation existed among treatments. The least significant difference multiple range test was used to determine the differences between means when overall differences were found. The oestrus rate of sows was analyzed using a $\chi^{2}$ test. All data are shown as mean \pm SEM except for oestrus rate, which was expressed in percentage. $P<0.05$ was considered to be statistically significant and $P<0.01$ was considered to be highly significant. Regarding sow and litter performance, the individual sow and her litter were used as the experimental unit.

\section{RESULTS}

\section{Animal Performance}

There was no significant difference in live born piglets, viability of piglets, average birth weight, oestrus interval, and survival rate of the first piglet observed due to YSE treatment (Table 2). However, supplementation with YSE in late gestation diets resulted in a trend toward reduced number of stillbirth piglets $(P=0.08)$ and weak piglets $(P=0.06)$ compared to the basal diet (Tables 2, 3). The survival rate of the last three piglets was increased from $90.00 \%$ in the control group to $96.67 \%$ in the group with $0.06 \%$ YSE supplementation in the present study. Pre-weanling mortality were reduced from $7.78 \%$ in the control group to $2.86 \%$ in the groups with $0.06 \%$ YSE supplementation without changes in average daily gain (ADG) during lactation. In addition, the diarrhea rate of suckling piglets was significantly reduced in the groups with YSE supplementation compared with the control group $(P=0.03)$. The supplementation of YSE leas to a lower trend of diarrhea rated of weanling piglets $(P=$ 0.06). Furthermore, the oestrus rate at day 5 and day 7 after weanling was effectively improved in all treatment groups with YSE supplementation.

\section{Nutrient Apparent Digestibility}

Apparent digestibility of dry matter was significantly higher in the sows fed 0.06 and $0.24 \%$ YSE supplement compared 
TABLE 2 | Effect of dietary YSE to sow reproduction performance.

\begin{tabular}{|c|c|c|c|c|c|}
\hline \multirow[t]{2}{*}{ Items } & \multicolumn{4}{|c|}{ Levels of YSE } & \multirow[t]{2}{*}{$P$-value } \\
\hline & 0 & $0.06 \%$ & $0.12 \%$ & $0.24 \%$ & \\
\hline Parity & $5.41 \pm 0.51$ & $6.00 \pm 0.49$ & $5.93 \pm 0.54$ & $5.13 \pm 0.41$ & 0.32 \\
\hline live born piglets/litter & $10.23 \pm 0.62$ & $10.00 \pm 0.37$ & $10.33 \pm 1.00$ & $10.31 \pm 0.71$ & 0.57 \\
\hline Stillbirth piglets/litter & $0.61 \pm 0.16$ & $0.41 \pm 0.21$ & $0.40 \pm 0.19$ & $0.50 \pm 0.20$ & 0.08 \\
\hline Weak piglets/litter & $0.22 \pm 0.10$ & $0.14 \pm 0.11$ & $0.13 \pm 0.09$ & $0.06 \pm 0.06$ & 0.06 \\
\hline Viability of piglets & $3.55 \pm 0.11$ & $3.78 \pm 0.13$ & $3.61 \pm 0.13$ & $3.64 \pm 0.18$ & 0.24 \\
\hline Average birth weight (kg) & $1.41 \pm 0.24$ & $1.39 \pm 0.14$ & $1.52 \pm 0.26$ & $1.45 \pm 0.24$ & 0.19 \\
\hline Birth litter weight (kg) & $13.29 \pm 1.65$ & $13.95 \pm 2.54$ & $14.30 \pm 3.00$ & $14.77 \pm 3.09$ & 0.09 \\
\hline Oestrus interval (d) & $4.89 \pm 0.78$ & $4.25 \pm 0.62$ & $4.51 \pm 0.77$ & $4.50 \pm 0.67$ & 0.16 \\
\hline Oestrus rate at D5 (\%) & $78.57 \pm 9.19^{a}$ & $87.50 \pm 8.92^{b}$ & $85.71 \pm 7.35^{b}$ & $81.81 \pm 7.19^{a b}$ & 0.04 \\
\hline Oestrus rate at D7 (\%) & $85.71 \pm 7.24^{\mathrm{a}}$ & $93.75 \pm 8.39^{b}$ & $92.86 \pm 9.77^{b}$ & $100^{\mathrm{b}}$ & 0.04 \\
\hline Survival rate of the first piglet (\%) & 100 & 100 & 100 & 100 & 0.18 \\
\hline Survival rate of the last 3 piglets (\%) & $90.00 \pm 3.18^{a}$ & $96.67 \pm 2.08^{b}$ & $90.48 \pm 4.14^{\mathrm{a}}$ & $91.67 \pm 2.11^{\mathrm{a}}$ & 0.04 \\
\hline
\end{tabular}

D5, Day 5 after weanling; D7, Day 7 after weanling.

Weak piglets: birth weight $<1.1 \mathrm{~kg}$.

${ }^{a, b}$ In a row, mean values with different superscript letters were significantly different $(P<0.05)$.

TABLE 3 | Effect of dietary YSE to piglet performance.

\begin{tabular}{|c|c|c|c|c|c|}
\hline \multirow[t]{2}{*}{ Items } & \multicolumn{4}{|c|}{ Levels of YSE } & \multirow[t]{2}{*}{$P$-value } \\
\hline & 0 & $0.06 \%$ & $0.12 \%$ & $0.24 \%$ & \\
\hline ADG (L2-7) & $180.83 \pm 9.04$ & $174.30 \pm 10.02$ & $174.87 \pm 15.40$ & $184.24 \pm 9.30$ & 0.32 \\
\hline ADG (L7-15) & $191.39 \pm 10.39$ & $197.06 \pm 9.86$ & $193.58 \pm 9.01$ & $195.70 \pm 7.82$ & 0.26 \\
\hline ADG (L15-21) & $186.50 \pm 10.41$ & $189.16 \pm 10.47$ & $202.38 \pm 11.04$ & $193.13 \pm 9.47$ & 0.34 \\
\hline ADG (L2-15) & $186.18 \pm 7.53$ & $185.69 \pm 9.19$ & $184.55 \pm 9.78$ & $189.97 \pm 7.91$ & 0.27 \\
\hline ADG (L2-21) & $186.24 \pm 6.45$ & $188.55 \pm 8.26$ & $189.83 \pm 9.37$ & $191.59 \pm 7.19$ & 0.23 \\
\hline ADG (L21-31) & $119.65 \pm 8.22$ & $117.43 \pm 9.05$ & $118.20 \pm 8.95$ & $121.06 \pm 6.61$ & 0.13 \\
\hline Mortality of piglets & $7.78 \pm 1.21^{a}$ & $2.86 \pm 2.01^{b}$ & $6.91 \pm 2.11^{a}$ & $6.25 \pm 2.52^{\mathrm{a}}$ & 0.04 \\
\hline Diarrhea rate of suckling piglets & $9.16 \pm 1.84^{a}$ & $3.64 \pm 0.69^{b}$ & $3.17 \pm 0.72^{b}$ & $4.77 \pm 1.07^{b}$ & 0.03 \\
\hline Diarrhea rate of weanling piglets & $6.58 \pm 2.06$ & $4.18 \pm 1.18$ & $6.73 \pm 1.61$ & $3.67 \pm 0.67$ & 0.06 \\
\hline
\end{tabular}

1) $A D G$, Average daily gain.

2) ${ }^{a, b}$ In a row, mean values with different superscript letters were significantly different $(P<0.05)$.

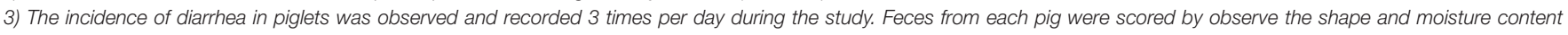

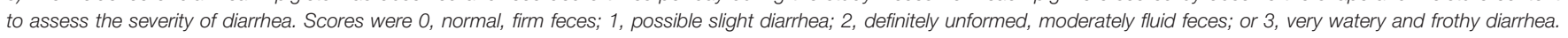
diarrhea incidence $(\%)=$ number of pigs with diarrhea/(number of pigs $\times$ total experimental days) $\times 100$.

to those in the control group during gestation $(P=0.04)$. Additionally, the apparent digestibility of fat was elevated by $10 \%$ in the groups with $0.06 \%$ YSE supplement compared to the control group during lactation $(P=0.03)$. No obvious changes in protein digestion were observed (Table 4), but the urine nitrogen (UN) levels in sow manure during both late gestation and lactation were significantly suppressed with all levels of YSE supplementation included in present study $(P=0.03$ and $P=$ 0.02 ), while the total protein (TP) level was only significantly increased in those sows during late gestation and lactation $(P$ $=0.02)$. There was a tendency to increase $\mathrm{TP}$ during late gestation in $0.24 \%$ treatment $(P=0.08)$ (Table 5). Among three supplementational levels, $0.06 \%$ YSE showed the best beneficial effect both on dry matter digestibility and fat digestibility.

\section{Blood Biochemical and Antioxidant Indices}

No significant differences in sow blood oxyhemoglobin were induced by YSE supplementation during either gestation or lactation. Changes in other biochemical parameters, including $\mathrm{pH}, \mathrm{pCO}_{2}, \mathrm{pO}_{2}, \mathrm{HCO}_{3}^{-}, \mathrm{TCO}_{2}$, and $\mathrm{NH}_{3}$ (Table 6), induced by the supplementation of YSE, were not identified either. However, 0.12 and $0.24 \%$ YSE supplementation significantly enhanced sow blood catalase (CAT) activity during gestation and lactation, while malonaldehyde (MDA) levels during gestation were significantly lower in sows with $0.06 \%$ YSE supplementation (Table 7).

\section{Total Nitrogen, Ammonia Nitrogen, Urea Nitrogen, and Urease Activity in Manure}

The results showed that initial total nitrogen contents and urea nitrogen in manure at $0 \mathrm{~h}$ of storage were significantly lower in those groups with 0.12 and $0.24 \%$ supplementation of YSE during gestation and lactation (Figures 1A,B, 2A,B). Besides, total nitrogen content in manure from gestating and lactating sows fed with 0.12 and $0.24 \%$ supplemental YSE continuously 
TABLE 4 | Effect of dietary YSE to nutrients apparent digestibility in gestating and lactating sow.

\begin{tabular}{|c|c|c|c|c|c|}
\hline \multirow[t]{2}{*}{ Items (apparent digestibility) } & \multicolumn{4}{|c|}{ Levels of YSE } & \multirow[t]{2}{*}{$P$-value } \\
\hline & 0 & $0.06 \%$ & $0.12 \%$ & $0.24 \%$ & \\
\hline \multicolumn{6}{|l|}{ D100 of gestation } \\
\hline Protein & $83.89 \pm 9.44$ & $84.09 \pm 8.43$ & $84.19 \pm 10.38$ & $84.16 \pm 6.17$ & 0.23 \\
\hline Fat & $63.56 \pm 5.59$ & $64.66 \pm 6.63$ & $63.60 \pm 5.53$ & $60.46 \pm 5.54$ & 0.14 \\
\hline Dry matter & $81.23 \pm 7.08^{a}$ & $87.64 \pm 8.07^{b}$ & $86.48 \pm 9.11^{b}$ & $82.58 \pm 9.18^{a}$ & 0.04 \\
\hline \multicolumn{6}{|l|}{ D15 of lactation } \\
\hline Protein & $87.03 \pm 0.54$ & $88.22 \pm 0.72$ & $88.35 \pm 0.78$ & $87.11 \pm 0.22$ & 0.34 \\
\hline Fat & $66.64 \pm 7.97^{a}$ & $72.15 \pm 6.04^{b}$ & $68.46 \pm 7.91^{\mathrm{ab}}$ & $68.53 \pm 7.41^{\mathrm{ab}}$ & 0.03 \\
\hline Dry matter & $84.61 \pm 0.43$ & $84.92 \pm 0.59$ & $84.70 \pm 0.74$ & $84.72 \pm 0.63$ & 0.29 \\
\hline
\end{tabular}

${ }^{a, b}$ In a row, mean values with different superscript letters were significantly different $(P<0.05)$.

TABLE 5 | The content of UN and TP in serum of sows with different levels of YSE supplementation.

\begin{tabular}{|c|c|c|c|c|c|c|}
\hline \multirow[t]{2}{*}{ Period } & \multirow[t]{2}{*}{ Items } & \multicolumn{4}{|c|}{ Levels of YSE } & \multirow[t]{2}{*}{$P$-value } \\
\hline & & 0 & $0.06 \%$ & $0.12 \%$ & $0.24 \%$ & \\
\hline \multirow[t]{2}{*}{ G100 } & UN (mmol/L) & $4.48 \pm 2.20^{\mathrm{a}}$ & $3.97 \pm 2.30^{\mathrm{b}}$ & $3.83 \pm 1.19^{\mathrm{b}}$ & $3.65 \pm 3.14^{b}$ & 0.03 \\
\hline & TP (g/L) & $66.15 \pm 2.76$ & $66.86 \pm 4.31$ & $67.07 \pm 2.40$ & $71.38 \pm 1.62$ & 0.08 \\
\hline \multirow[t]{2}{*}{ L15 } & $\mathrm{UN}$ (mmol/L) & $6.32 \pm 4.61^{a}$ & $5.72 \pm 3.24^{\mathrm{ab}}$ & $4.96 \pm 4.52^{b}$ & $4.81 \pm 3.27^{b}$ & 0.02 \\
\hline & $\mathrm{TP}(\mathrm{g} / \mathrm{L})$ & $66.37 \pm 5.58^{A}$ & $67.97 \pm 4.38^{\mathrm{A}}$ & $72.21 \pm 6.77^{\mathrm{B}}$ & $77.94 \pm 8.24^{\mathrm{B}}$ & 0.007 \\
\hline
\end{tabular}

1) UN, Urine nitrogen; TP, Total protein.

2) ${ }^{a, b}$ In a row, mean values with different superscript letters were significantly different $(P<0.05)$.

decreased at $12 \mathrm{~h}$ of storage, but this trend disappeared at $24 \mathrm{~h}$ and then reversed at $48 \mathrm{~h}$ and until to $120 \mathrm{~h}$ (Figures 1A,B). The total nitrogen contents in manure of both gestation and lactation was significantly higher in those sows supplemented with YSE compared with control sows during 48-120 h of storage (Figures 1A,B).

We further calculated the nitrogen loss of manure during storage and, interestingly found that all groups with YSE supplementation had less nitrogen loss during the entire storage period (Figures 1C,D). The loss of urea nitrogen during storage in the groups with YSE supplementation showed significantly lower values compared with the control group during gestation and lactation (Figures 2C,D), with the results being consistent with the trend of total nitrogen content.

The contents of ammonia nitrogen in manure from those lactating and gestating sows supplemented with YSE were significantly higher during the entire storage compared with the control group (Figures 3A,B). However, the loss of ammonia nitrogen in manure was significantly less than in those groups with YSE supplementation during both gestation and lactation (Figures 3C,D). We did not observe a significant effect of YSE supplementation on urease activity in manure during gestation or lactation (Figure 4).

\section{DISCUSSION}

\section{Animal Performance}

The positive effects of dietary supplementation of YSE on growth rate, feed efficiency, and animal health during the grower period has been reported in previous studies (15-18). However, there have been limited investigations focusing on the sow production. In the present study, we evaluated the effect of YSE supplementation on sow and litter performance from late pregnancy (G100) to lactation (L21), with the results shown in Tables 2, 3. The results of our study are in accordance with the report of Cline, who either did not find a beneficial effect of supplementing YSE in sow diets on prenatal growth of piglets, but observed significant reduced stillbirth occurrence (41.2\%) (19). Herpin et al. also reported that the number and percentage of stillbirths per litter were reduced from 0.78 and $7.2 \%$ to 0.5 and $4.7 \%$, respectively when YSE powder was supplemented into the gestational sow diet (20). In addition, increased survival rate of the last three piglets and decreased piglet mortality and diarrhea rate in present study further confirmed the beneficial effect of YSE on sow performance and postnatal growth in piglets. We observed that all levels of YSE supplemetantion significantly improved diarrhea rate of suckling piglets but no obviouse affect on diarrhea rate of weaning piglets (Table 3). This result might because that YSE could improve piglets diarrhea rate by increasing antioxidative capacity, but oxidative stress during weanling was too extensive to eliminate only by supplementation of YSE, which resulting in no significant change in diarrhea rate of weanling pielets. It is interesting that this benefit disappeared when the supplementation were increased up to $0.12 \%$ and $0.24 \%$ indicating $0.06 \%$ supplementaion would be the optimal dose for animal performance during late gestataion and lactation. Yucca is a source of steroid saponins that have phyto-estrogenic effects through binding to estrogen receptors 
TABLE 6 | Effect of dietary YSE to blood gas in gestating and lactating sow.

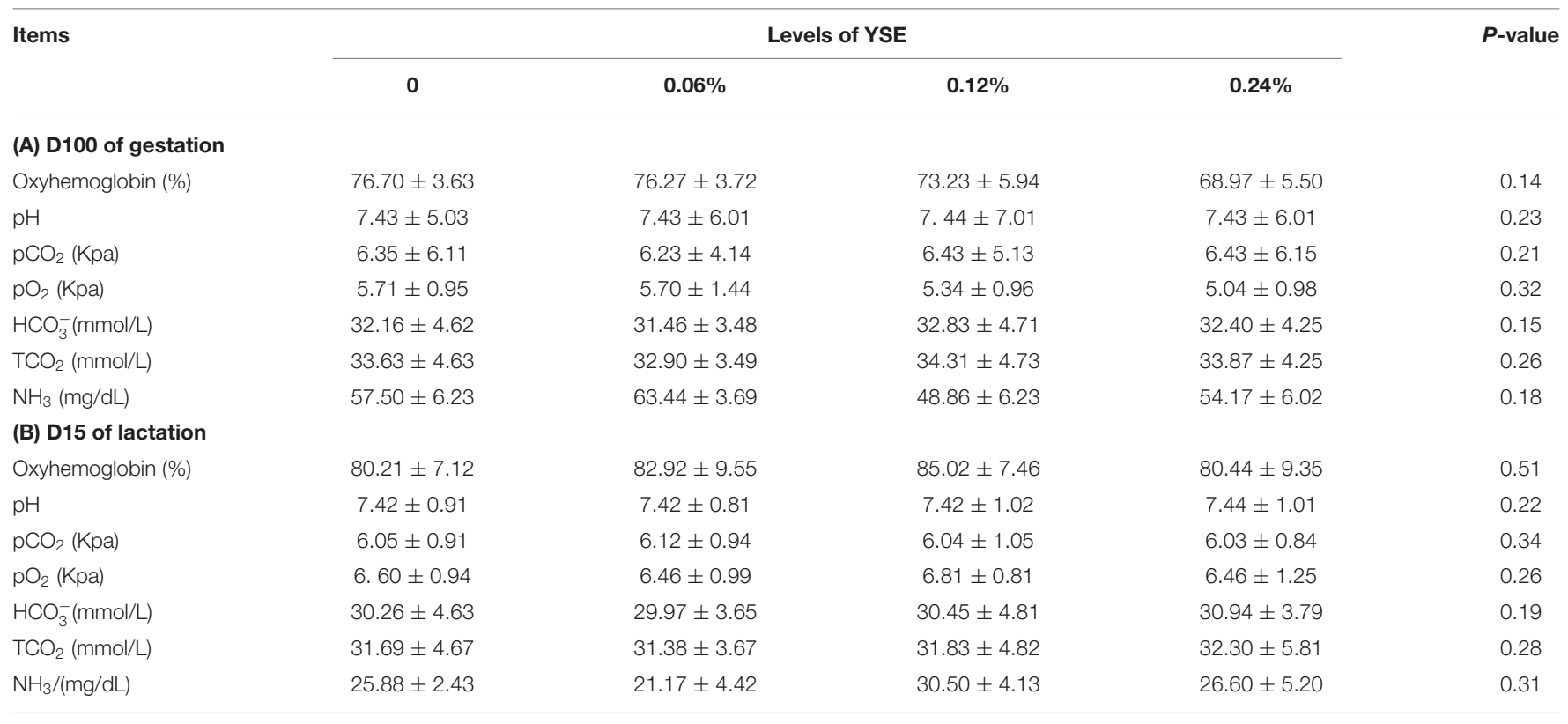

In a row, $P<0.05$ means values were not significantly different.

TABLE 7 | Effect of dietary YSE to blood antioxidative parameter in gestating and lactating sow.

\begin{tabular}{|c|c|c|c|c|c|}
\hline Items & \multicolumn{4}{|c|}{ Levels of YSE } & $P$-value \\
\hline T-AOC (U/mL) & $6.93 \pm 1.00$ & $6.50 \pm 0.42$ & $7.11 \pm 0.61$ & $6.94 \pm 0.75$ & 0.14 \\
\hline GSH-PX (IU) & $706.83 \pm 37.36$ & $791.30 \pm 71.53$ & $855.07 \pm 80.69$ & $804.35 \pm 73.99$ & 0.23 \\
\hline CAT (U/mL) & $1.52 \pm 0.42^{\mathrm{a}}$ & $1.74 \pm 0.38^{\mathrm{ab}}$ & $2.71 \pm 0.41^{\mathrm{b}}$ & $2.83 \pm 0.46^{b}$ & 0.02 \\
\hline \multicolumn{6}{|c|}{ (B) D15 of lactation } \\
\hline T-AOC (U/mL) & $5.11 \pm 0.83$ & $6.66 \pm 0.49$ & $5.55 \pm 0.66$ & $6.58 \pm 1.64$ & 0.51 \\
\hline GSH-PX (IU) & $627.82 \pm 87.02$ & $731.88 \pm 96.39$ & $739.13 \pm 92.15$ & $693.91 \pm 61.94$ & 0.22 \\
\hline $\mathrm{SOD}(\mathrm{U} / \mathrm{mL})$ & $64.51 \pm 1.60$ & $62.95 \pm 0.80$ & $61.18 \pm 2.79$ & $63.68 \pm 1.77$ & 0.34 \\
\hline
\end{tabular}

MDA, Malonaldehyde; CAT, Catalase; T-AOC, Total antioxidant capacity; SOD, Superoxide dismutase; GSH-Px, Glutathione peroxidase; GSH, Glutathione.

$a, b$ In a row, mean values with different superscript letters were significantly different $(P<0.05)$.

and consequently affect those processes regulated by estrogen (21-23). Several previous studies reported that addition of yucca in feed positively affects ovarian function and influences the reproductive process in cattle, rabbits, pig and goat (24-26). In the present study, the increased oestrus rate at day 5 and day 7 with YSE supplementation might be due to the fact that the steroid saponins contained in YSE have a certain promoting effect on the recovery of ovarian and uterus after pregnancy (27).
We also determined the effect of YSE supplementation on nutrient apparent digestibility and the results with higher dry matter and fat digestibly are consistent with the previous study conducted by Min et al., who reported addition of yucca extracts to the diet showed significantly higher dry matter, crude ash and crude protein digestibility (28). Lila et al. also showed beneficial effects of YSE on ruminal ammonia levels, DM digestibility and rumen $\mathrm{pH}$ in lactating cows (29). The beneficial effect of YSE on nutrient utilization might be attributed to the characteristic 


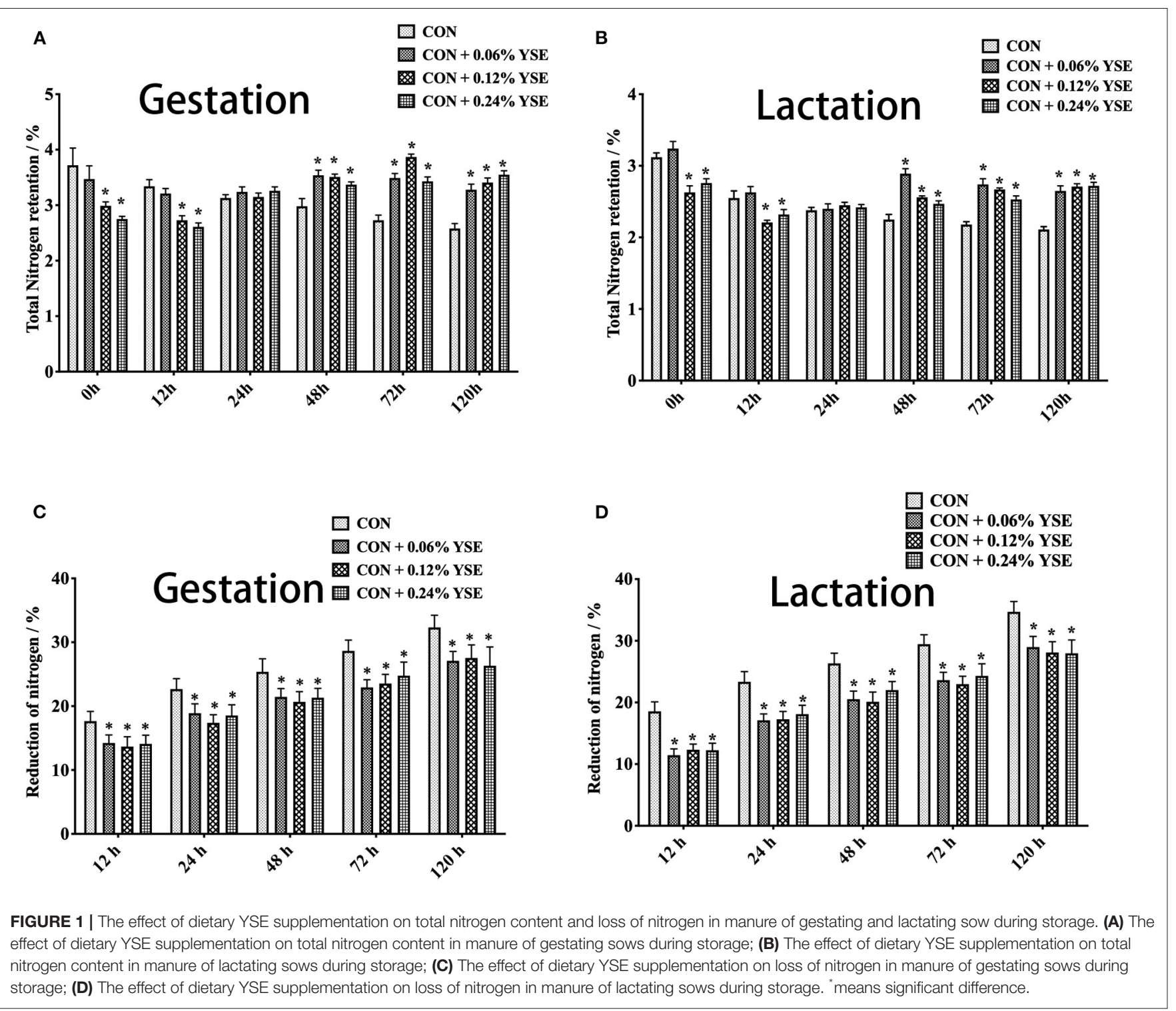

properties of saponins, the main active components in yucca extract, to promote fat emulsification due to its surface-activity and the capacity to delay the passage of intestinal chyme (30).

\section{Blood Biochemical and Antioxidative Indices}

Deficiency in blood oxygen supply has been considered to be a crucial factor in fetal and piglet death during gestation, parturition and lactation $(31,32)$. Our results showed clearly that supplementation of YSE effectively decreased fetal and piglet mortality during the entire reproductive cycle. Cline showed that supplementation of YSE to sows prior to the start of farrowing resulted in increased blood oxygen supply to the fetus during parturition (19), which could be the reason for fewer stillbirths and decreased pre-weaning mortality. However, Heprin et al. observed no obvious changes in oxygen content either in the umbilical cord vein at birth or in the umbilical artery at $1 \mathrm{~h}$ after birth with the supplementation of YSE, and they proposed that beneficial effects of YSE on blood oxygen content were only significant in sub-optimal oxygenated conditions (20). In our present study, no significant differences in sow blood oxyhemoglobin were induced by YSE supplementation during either gestation or lactation. The different oxygenated conditions, which were the result of variations in the rearing environment and feed composition, might be the reason for the contradictory results in these studies remaining to be addressed by future investigations.

A number of previous studies have reported that YSE can effectively relieve oxidative damage in various species, including the rat, cattle, and sheep (33-35). However, there have been few studies on the effect of YSE on antioxidative function in pig, especially in sow. In the study described herein, we determined blood antioxidant parameters to evaluate the protective role of dietary supplementation of YSE against basal oxidative 

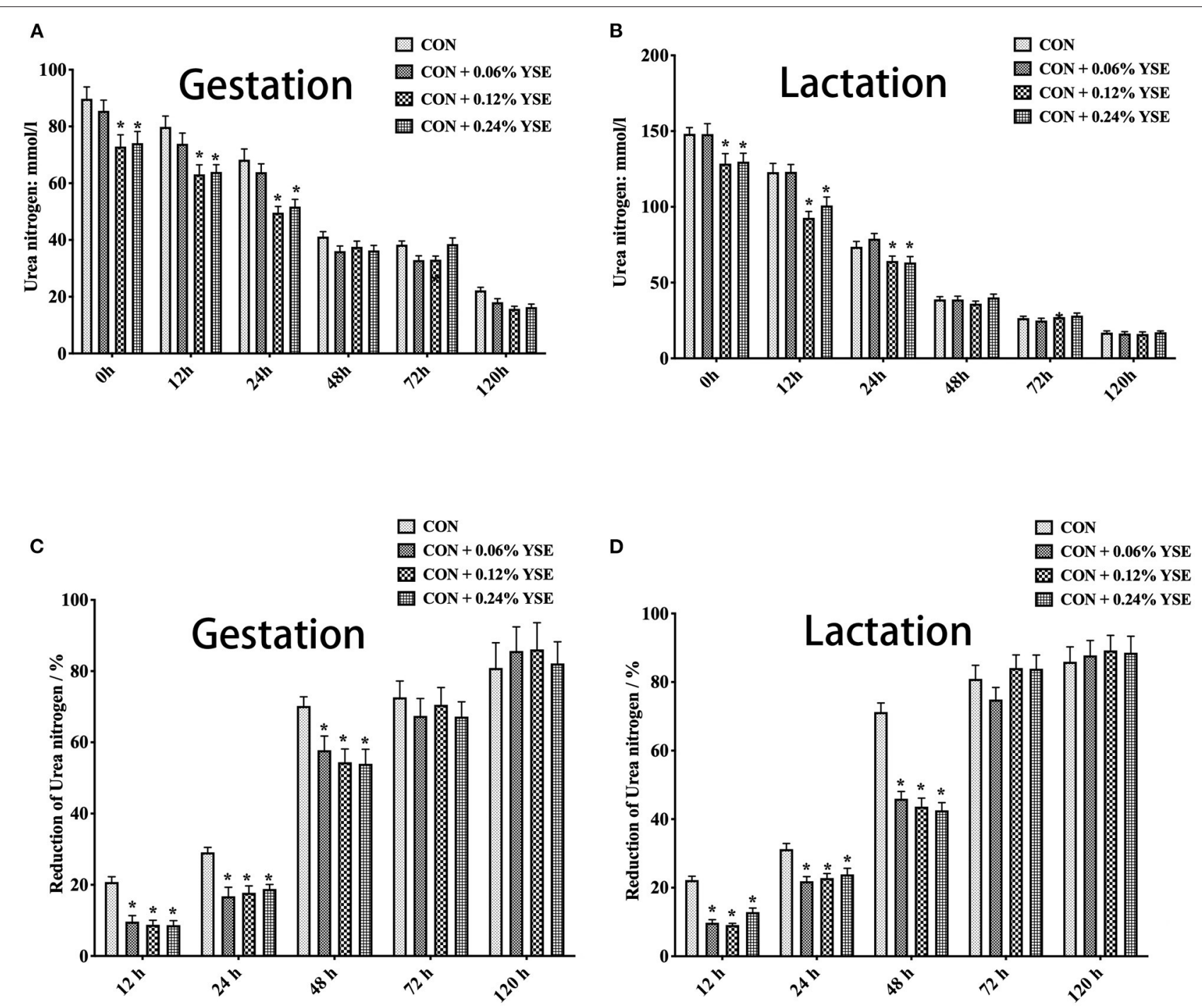

FIGURE 2 | The effect of dietary YSE supplementation on urea nitrogen content and loss of urea nitrogen in manure of gestating and lactating sows during storage. (A) The effect of dietary YSE supplementation on urea nitrogen content in manure of gestating sows during storage; (B) The effect of dietary YSE supplementation on urea nitrogen content in manure of lactating sows during storage; (C) The effect of dietary YSE supplementation on loss of urea nitrogen in manure of gestating sows during storage; (D) The effect of dietary YSE supplementation on loss of urea nitrogen in manure of lactating sows during storage. *means significant difference.

damage, both in sows and piglets. The results showed that YSE supplementation significantly enhanced sow antioxidative status and these observations were consistent with previous studies in other species. It has been suggested that the benefit of YSE as a natural antioxidant can be attributed to the phenolic hydroxyl groups included in yucca, which serve as hydrogen donors to the peroxy radicals produced by lipid oxidation, thus suppressing the formation of hydroxyl peroxide $(33,36)$.

\section{Total Nitrogen, Ammonia Nitrogen, Urea Nitrogen, and Urease Activity in Manure}

Nitrogen in animal manure, including urea nitrogen and undigested protein from feed, could be hydrolyzed by fecal microbial ureases to be ammonia and then volatilized to the atmosphere, which results in loss of nitrogen in manure and increase in ammonia release during storage (37). YSE has been reported to reduce ammonia emission from animal manure in several previous studies. Piacente et al. showed the positive effects of dietary YSE supplementation to different animals on ammonia levels in air (38). Santacruz-Reyes and Chien reported that the application of YSE in water or feed could reduce the accumulation of ammonia in wastewater discharge during shrimp production (39). Saeed et al. (9) reported that YSE could mitigate ammonia emissions from poultry manure and promoted animal health and production. In present study, we tracked the temporal change of total nitrogen and urea nitrogen in sow manure during storage and found that 0.12 and $0.24 \%$ YSE inclusion in sow diet could improve protein utilization in both gestating and lactating sows (Figures 1A,B, 2A,B), which result were consistent with our results about 


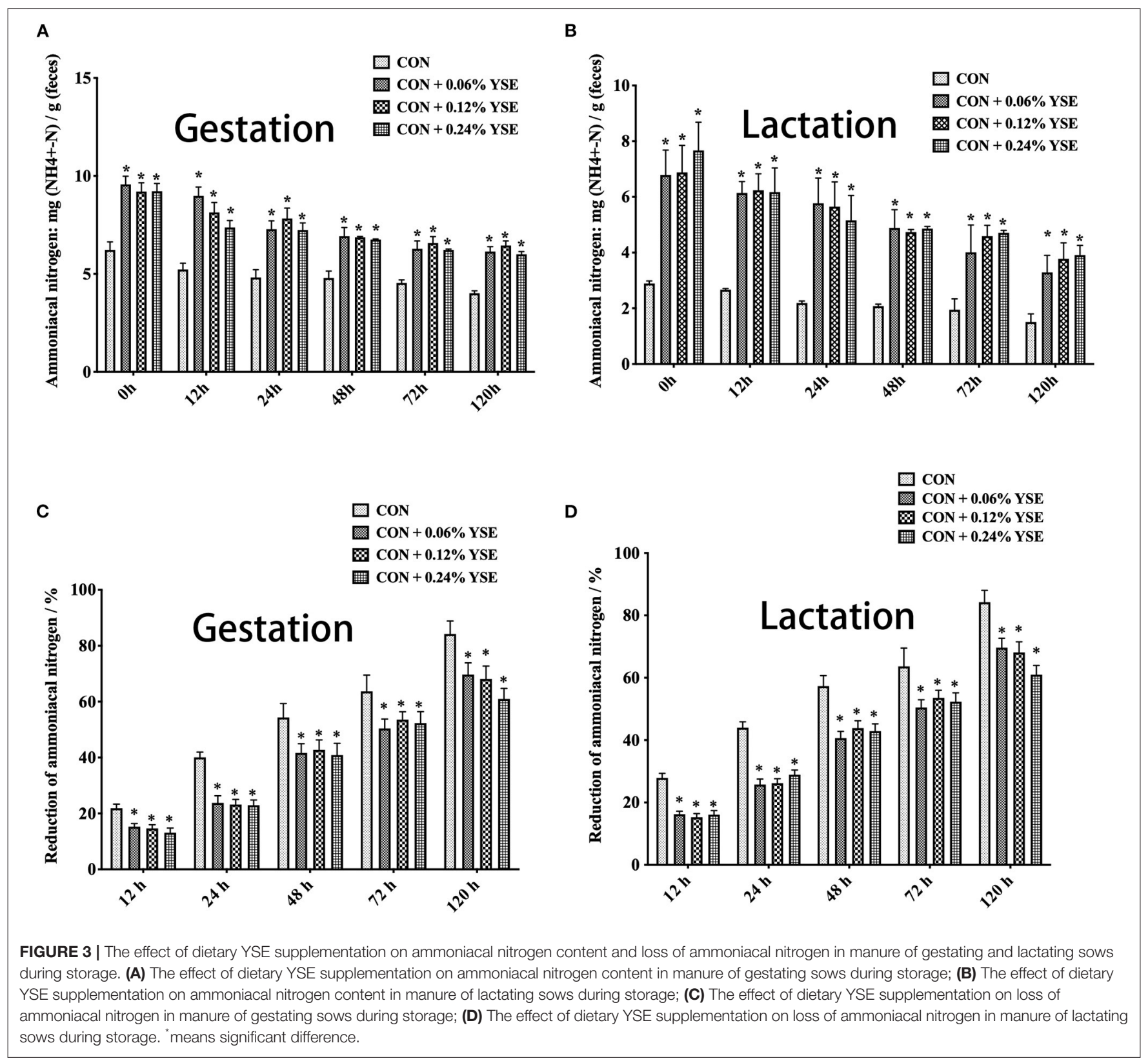

the effect of YSE to nutrients digestation in present study. The change of total nitrogen contents and urea nitrogen at different time point of storage might be due to higher microbial degradation rate at the begin of storage because of more abundant nutrients when manure was relatively fresh, and then microbial degradation rate decreased with time because of exhaustion of the nutrient supply by microbes (40). Although the level of $0.06 \%$ YSE supplementation were too low to lead to significant change on total nitrogen and urea nitrogen content of sow manure, all levels of supplementation of YSE could greatly decreased the reduction of total nitrogen and urea nitrogen of sow manure, implying the beneficial effect of YSE addition to reduce ammonia emissions of sow manure during storage.
The beneficial effect of YSE to control ammonia emission from animal manure has been observed in previous and our present studies, there is still much controversy surrounding the mechanism by which YSE has a positive effect in reducing ammonia volatilization. Makkar et al. and Cunningham and Morrison reported that YSE may efficiently entrap ammonia nitrogen in wheat straw ingested into the rumen of the cow, a potentially advantageous situation as it could lead to lower emission of polluting gases (41-43). Headon and Dawson and $\mathrm{Wu}$ et al. also pointed out that YSE has ammonia-binding properties due to the presence of a glycoprotein $(44,45)$, which plays an important role in reducing ammonia output from animal excretions. Inconsistently, other reports indicate that the beneficial effect of YSE on ammonia emission reduction should 


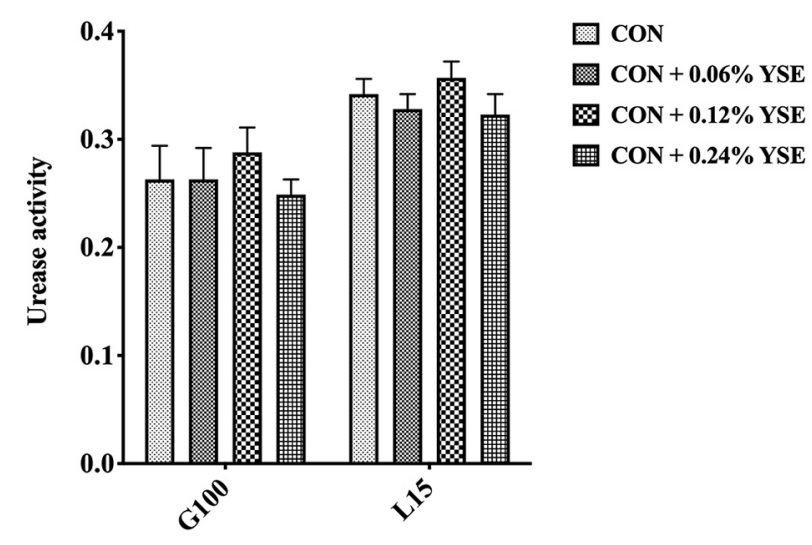

FIGURE 4 | The effect of YSE supplementation on urease activity in sow manure during gestation and lactation.

be attributed to the fact that its saponin fractions inhibit the activity of urease on the decomposition of urea nitrogen to be ammonia $(46,47)$.

The conversion from organic nitrogenous materials to ammonia is an enzymatic reaction, in which urease plays an important role as the limiting enzyme for the last step and ammonia nitrogen is included as key intermediate product $(48,49)$. The higher content of ammonia nitrogen in manure would lead to suppression of $\mathrm{NH}_{3}$ release. Thus, with the intent to answer the question as to how YSE reduces the emission of ammonia, we determined urease activity, ammonia nitrogen, and loss of ammonia nitrogen in manure at different time points of storage. The results showed that ammonia nitrogen content in sows feces supplemented with all levels of YSE included in previous study during lactation and pregnancy was significantly higher than that in the control group throughout the storage process (Figures 3A,B), while the loss of ammonia nitrogen in manure was significantly less than in those groups with YSE supplementation during both gestation and lactation (Figures 3C,D), which implying more ammonia nitrogen were kept in manure and could not be convert to ammonia to emit into air. Combining to the observation that no significant change of urease activity in manure in the group with YSE supplementation, which results are also consistent with the in vivo or in vitro study's of Killeen et al. (50, 51), we speculate that YSE might entrap ammonia nitrogen in manure to reduce ammonia emission during storage.

\section{REFERENCES}

1. Matusiak K, Oleksy M, Borowski S, Nowak A, Korczyński M, Dobrzański $\mathrm{Z}$, et al. The use of Yucca schidigera and microbial preparation for poultry manure deodorization and hygienization. J Environ Manage. (2016) 170:509. doi: 10.1016/j.jenvman.2016.01.007

\section{CONCLUSION}

In summary, results from this study indicate that $0.06 \%$ supplementation of YSE in the sow diet during gestation and lactation could improve sow reproductive performance with increased survival rate of the last three piglets, as well as reduced pre-weanling mortality and diarrhea rate in the piglets. Besides, $0.06,0.12$, and $0.24 \%$ YSE supplementation could reduce loss of total nitrogen and urea nitrogen in sow manure, while decreasing ammonia emission by binding ammonia nitrogen and inhibiting its degradation. The results of this study provided practical information about application of YSE (optimal supplementation level for different physiological stages) in sow diet to improve reproductive performance and reduce ammino emission in pig industry. Further investigation are needed to performed to study the effect of YSE to milk quality which might be the crucial reason for reduced mortality rate of piglets in present study.

\section{DATA AVAILABILITY STATEMENT}

The raw data supporting the conclusions of this article will be made available by the authors without reservation.

\section{ETHICS STATEMENT}

The animal study was reviewed and approved by South China Agricultural University.

\section{AUTHOR CONTRIBUTIONS}

Material preparation, data collection, and analysis were performed by CW, PZ, and CC. The first draft of the manuscript was written by FC and WG. All authors contributed to the study conception and design, commented on previous versions of the manuscript, read, and approved the final manuscript.

\section{FUNDING}

This research was supported by National Natural Science Foundation of China (No. 31402082) and National Key R\&D Program of China (No. 2018YFD0501000).

\section{ACKNOWLEDGMENTS}

The authors thank the National Key R\&D Program of China (No. 2018YFD0501000) and National Natural Science Foundation of China (No. 31402082) for supporting this study.

2. Rappert S, Müller R. Odor compounds in waste gas emissions from agricultural operations and food industries. Waste Manage. (2005) 25:887907. doi: 10.1016/j.wasman.2005.07.008

3. Cheeke RP, Piacente, S, Oleszek W. Anti-inflammatory and antiarthritic effects of yucca schidigera: A review. J Inflamm. (2006) 3:6. doi: 10.1186/1476-9255-3-6 
4. Price K, Johnson I, Fenwick G, Malinow M. The chemistry and biological significance of saponins in foods and feedingstuffs. Crit Rev Food Sci Nutr. (1987) 26:27-135. doi: 10.1080/10408398709527461

5. Kaya S, Erdogan Z, Erdogan S. Effect of different dietary levels of Yucca schidigera powder on the performance, blood parameters and egg yolk cholesterol of laying quails. J Vet Med Series A. (2003) 50:147. doi: 10.1046/j.1439-0442.2003.00487.x

6. Mader T, Brumm M. Effect of feeding sarsaponin in cattle and swine diets. $J$ Anim Sci. (1987) 65:9-15. doi: 10.2527/jas1987.6519

7. Sahoo PS, Kaur D, Sethi A, Sharma A, Chandra M. Evaluation of Yucca schidigera extract as feed additive on performance of broiler chicks in winter season. Vet World. (2015) 8:556-60. doi: 10.14202/vetworld.2015.5 56-560

8. Chepete H, Xin H, Mendes BL, Li H, Bailey T. Ammonia emission and performance of laying hens as affected by different dosages of Yucca schidigera in the diet. J Appl Poultry Res. (2012) 21:522-30. doi: 10.3382/japr.201100420

9. Saeed M, Arain AM, Naveed M, Alagawany M, El-Hack AME, Bhutto AZ, et al. Yucca schidigera can mitigate ammonia emissions from manure and promote poultry health and production. Environ Sci Pollut Res. (2018) 25:35027-33. doi: 10.1007/s11356-018-3546-1

10. Santacruz-Reyes AR, Chien Y-H. Yucca schidigera extract-A bioresource for the reduction of ammonia from mariculture. Biores Technol. (2010) 101:56527. doi: 10.1016/j.biortech.2010.01.127

11. De Jong AJ, Derouchey MJ, Tokach DM, Dritz SS, Goodband DR, Paulk $\mathrm{C}$, et al. Effects of wheat source and particle size in meal and pelleted diets on finishing pig growth performance, carcass characteristics, nutrient digestibility. J Anim Sci. (2016) 94:3303-11. doi: 10.2527/jas.2016-0370

12. Chen J, Han J, Guan W, Chen F, Wang C, Zhang Y, et al. Effect on selenium status and antioxidant status of the progeny. Anim Feed Sci Technol. (2016) 221:101-10. doi: 10.1016/j.anifeedsci.2016.08.021

13. Deutch C. Limited effectiveness of over the counter plant preparations used for the treatment of urinary tract infections as inhibitors of the urease activity from Staphylococcus saprophyticus. J Appl Microbiol. (2017) 122:13808. doi: 10.1111/jam.13430

14. Wang Y, Chen Y, Cho HJ, Yoo SJ, Huang Y, Kim JH, et al. Effect of soybean hull supplementation to finishing pigs on the emission of noxious gases from slurry. Anim Sci J. (2009) 80:316-21. doi: 10.1111/j.1740-0929.2009. 00637.x

15. Sun D, Jin X, Shi B, Su J, Tong M, Yan S. Dietary Yucca schidigera extract improved growth performance and liver antioxidative function in broilers. Italian J Anim Sci. (2017) 16:677-84. doi: 10.1080/1828051X.2017.1302826

16. Földešiová M, BaláŽi, A, Chrastinová L, Pivko J, Kotwica J. Yucca schidigera can promote rabbit growth, fecundity, affect the release of hormones in vivo and in vitro, induce pathological changes in liver, and reduce ovarian resistance to benzene. Anim Reproduct Sci. (2017) 183:667. doi: 10.1016/j.anireprosci.2017.06.001

17. Sahoo PS, Kaur D, Sethi S, Chandrahas AP, Chandra M. Effect of dietary supplementation of yucca schidigera extract on the performance and litter quality of broilers in winter season. Anim Nutr Feed Technol. (2016) 16:47584. doi: 10.5958/0974-181X.2016.00043.3

18. Sun D, Jin X, Camerlink I, Tong M, Su J, Zhao F, et al. Effects of Yucca schidigera extract on growth performance and antioxidative function of small intestine in broilers. J Anim Physiol Anim Nutr. (2019) 103:73846. doi: 10.1111/jpn.13067

19. Cline J. Effect of feeding MICRO-AID on stillbirths, preweaning mortality, blood oxygen values of piglets and blood urea nitrogen in sows. J Anim Sci. (1996) $74: 189$.

20. Herpin P, Vincent A, Cheeke P. Effect of feeding Yucca schidigera (DK powder) to the sow on piglet blood oxygenation and survival. Proc Am Soc Anim Sci Western Section. (2004) 55:145-50.

21. Francis G, Kerem Z, Makkar PH, Becker K. The biological action of saponins in animal systems: a review. Br J Nutr. (2002) 88:587605. doi: 10.1079/BJN2002725

22. Jefferson NW, Patisaul BH, Williams CJ. Reproductive consequences of developmental phytoestrogen exposure. Reproduction. (2012) 143:24760. doi: 10.1530/REP-11-0369
23. Sirotkin VA, Harrath AH. Phytoestrogens their effects. Eur J Pharmacol. (2014) 741:230-6. doi: 10.1016/j.ejphar.2014.07.057

24. Balázi A, Földesiová M, Chrastinová L, Sirotkin VA, Chrenek P. Effect of the herbal additive "Yucca" on rabbit spermatozoa characteristics. J Microbiol Biotechnol Food Sci. (2013) 2:1829-37.

25. Cheeke PR. Actual and Potential Applications of Yucca Schidigera and Quillaja Saponaria Saponins in Human and Animal Nutrition. J Anim Sci. (2000) 45:241-54. doi: 10.1007/978-94-015-9339-7_25

26. Štochmalová A, Kadasi A, Alexa R, Grossman R, Sirotkin A. The effect of yucca on proliferation, apoptosis, and steroidogenesis of porcine ovarian granulosa cells. Potravinarstvo Sci J Food Industry. (2014) 8:8791. doi: 10.5219/357

27. Vlčková R, Sopková D, Andrejčáková Z, Valocký I, Kádasi A, Harrath HA, et al. Dietary supplementation of yucca (Yucca schidigera) affects ovine ovarian functions. Theriogenology. (2017) 88:158-65. doi: 10.1016/j.theriogenology.2016.09.026

28. Min ST, Kim DJ, Tian ZJ, Cho TW, Hyun Y, Sohn SK, et al. Effects of yucca extracts and protein levels on growth performance and nutrient utilization in growing pigs. Asian-Austr J Anim Sci. (2001) 14:619. doi: 10.5713/ajas.2001.61

29. Lila AZ, Mohammed N, Kanda S, Kurihara M, Itabashi H. Sarsaponin effects on ruminal fermentation and microbes, methane production, digestibility and blood metabolites in steers. Asian Austr J Anim Sci. (2005) 18:174651. doi: 10.5713/ajas.2005.1746

30. Johnson TI, Gee MJ, Price K, Curl C, Fenwick GR. Influence of saponins on gut permeability and active nutrient transport in vitro. J Nutr. (1986) 116:2270-7. doi: 10.1093/jn/116.11.2270

31. Alonso-Spilsbury M, Mota-Rojas D, Villanueva-Garcia D, MartinezBurnes J, Orozco H, Ramirez-Necoechea R, et al. Perinatal asphyxia pathophysiology in pig and human: a review. Anim Reprod Sci. (2005) 90:1-30. doi: 10.1016/j.anireprosci.2005.01.007

32. Nuntapaitoon M, Miuns R, Tummaruk P. Newborn traits associated with preweaning growth and survival in piglets. Asian-Australas J Anim Sci. (2018) 31:237-44. doi: 10.5713/ajas.16.0962

33. Alagawany MM, Farag RM, Dhama K. Nutritional biological effects of turmeric (Curcuma longa) supplementation on performance, serum biochemical parameters oxidative status of broiler chicks exposed to endosulfan in the diets. Asian J Anim Vet Adv. (2015) 10:86-96. doi: 10.3923/ajava.2015.86.96

34. Cigerci HI, Fidan FA, Konuk M, Yuksel H, Kucukkurt I, Eryavuz A, et al. The protective potential of Yucca schidigera (Sarsaponin 30ß) against nitrite-induced oxidative stress in rats. J Nat Med. (2009) 63:3117. doi: 10.1007/s11418-009-0338-4

35. Kucukkurt I, Ince S, Fidan FA, Ozdemir A. The effects of dietary supplementation of different amount of Yucca schidigera powder (Sarsaponin. 30®) on blood and tissue antioxidant defense systems and lipid peroxidation in rats. J Anim Vet Adv. (2008) 7:1413-7.

36. Hashemipour H, Kermanshahi H, Golian A, Veldkamp T. Effect of thymol and carvacrol feed supplementation on performance, antioxidant enzyme activities, fatty acid composition, digestive enzyme activities, and immune response in broiler chickens. Poultry Sci. (2013) 92:205969. doi: $10.3382 / \mathrm{ps} .2012-02685$

37. Levičnik-Höfferle Š, Nicol WG, Ausec L, Mandić-Mulec I, Prosser JI. Stimulation of thaumarchaeal ammonia oxidation by ammonia derived from organic nitrogen but not added inorganic nitrogen. FEMS Microbiol Ecol. (2012) 80:114-23. doi: 10.1111/j.1574-6941.2011.01275.x

38. Piacente, S, Pizza, C, Oleszek W. Saponins and phenolics of Yucca. Schidigera Roezl: chemistry and bioactivity. Phytochem Rev. (2005) 4:17790. doi: 10.1007/s11101-005-1234-5

39. Santacruz-Reyes AR, Chien Y-H. The potential of Yucca schidigera extract to reduce the ammonia pollution from shrimp farming. Biores Technol. (2012) 113:311-4. doi: 10.1016/j.biortech.2012.02.132

40. Kirchman H. Ammonia volatilization during aerobic and anaerobic manure decomposition. Plant Soil. (1989) 115:35-41. doi: 10.1007/BF022 20692

41. Makkar HP, Sen S, Blümmel M, Becker K. Effects of fractions containing saponins from Yucca schidigera, Quillaja saponaria, and Acacia 
auriculoformis on rumen fermentation. J Agri Food Chem. (1998) 46:4324-8. doi: 10.1021/jf980269q

42. Makkar H, Aregheore E, Becker K. Effect of saponins and plant extracts containing saponins on the recovery of ammonia during urea-ammoniation of wheat straw and fermentation kinetics of the treated straw. J Agricul Sci. (1999) 132:313-21. doi: 10.1017/S0021859699006334

43. Cunningham, D, Morrison W. Dietary energy and fat content as factors in the nutrition of developing egg strain pullets and young hens: 3 . effects on hepatic lipogenic enzyme activity and body chemical composition during the first 20 weeks of lay. Poultry Sci. (1977) 56:1783-91. doi: 10.3382/ps.0561783

44. Headon D, Dawson K. Yucca extract controls atmospheric ammonia levels. Feedstuffs. (1990) 62:15-6.

45. Wu Z, Sadik M, Sleiman F, Simas J, Pessarakli M, Huber J. Influence of yucca extract on ruminal metabolism in cows. J Anim Sci. (1994) 72:103842. doi: $10.2527 / 1994.7241038 \mathrm{x}$

46. Anthony BN, Balog MJ, Staudinger BF, Wall WC, Walker DR, Huff WE. Effect of a urease inhibitor and ceiling fans on ascites in broilers. 1. Environmental variability and incidence of ascites. Poult Sci. (1994) 73:8019. doi: 10.3382/ps.0730801

47. Preston LR, Bartle JS, May T, Goodall SR. Influence of sarsaponin on growth, feed and nitrogen utilization in growing male rats fed diets with added urea or protein. J Anim Sci. (1987) 65:481-7. doi: 10.2527/jas1987.652481x

48. Bitzer CC, Sims JT. Estimating the availability of nitrogen in poultry manure through laboratory and field studies. J Environ Q. (1988) 17:4754. doi: $10.2134 /$ jeq1988.00472425001700010007x
49. Nahm K. Evaluation of the nitrogen content in poultry manure. World Poultry Sci J. (2003) 59:77-88. doi: 10.1079/WPS20030004

50. Killeen FG, Connolly RC, Walsh AG, Duffy FC, Headon RD, Power RF. The effects of dietary supplementation with Yucca schidigera extract or fractions thereof on nitrogen metabolism and gastrointestinal fermentation processes in the rat. J Sci Food Agricul. (1998) 76:919. doi: 10.1002/(SICI)1097-0010(199801)76:1<91::AID-JSFA926>3. $0 . \mathrm{CO} ; 2-\mathrm{H}$

51. Killeen GF, Madigan AC, Connolly RC, Walsh AG, Clark C, Hynes JM, et al. Antimicrobial saponins of Yucca schidigera and the implications of their in vitro properties for their in vivo impact. J Agricul Food Chem. (1998) 46:3178-86. doi: 10.1021/jf97 $0928 \mathrm{j}$

Conflict of Interest: The authors declare that the research was conducted in the absence of any commercial or financial relationships that could be construed as a potential conflict of interest.

Copyright (c) 2021 Chen, Lv, Zhu, Cui, Wu, Chen, Zhang and Guan. This is an open-access article distributed under the terms of the Creative Commons Attribution License (CC BY). The use, distribution or reproduction in other forums is permitted, provided the original author(s) and the copyright owner(s) are credited and that the original publication in this journal is cited, in accordance with accepted academic practice. No use, distribution or reproduction is permitted which does not comply with these terms. 